\title{
LA BATALLA DEL METROPOLITANO. PROTESTA MUNICIPAL Y CONFLICTO POLÍTICO EN MADRID A FINALES DE LA RESTAURACIÓN
}

THE BATTLE OF SUBWAY. MUNICIPAL PROTEST AND POLITICAL CONFLICT IN MADRID AT THE END OF THE RESTORATION

\author{
Santiago de Miguel Salanova* \\ Universidad Complutense de Madrid. España
}

\begin{abstract}
RESUMEN: Este artículo analiza el proceso de construcción y desarrollo inicial del ferrocarril metropolitano en Madrid, indagando en los conflictos de intereses jurídicos y políticos que suscitó entre los tres organismos implicados en él: el gobierno municipal de la ciudad, la empresa concesionaria del transporte y el Estado. El objetivo será comprender el posicionamiento que el primero de ellos mostró en un contexto muy específico de efervescencia de la acción política municipal, caracterizado por la reivindicación de mayores atribuciones en la gestión de los principales servicios de utilidad pública local. Para cubrir este propósito se atenderá no sólo a las reclamaciones que presentó contra las intervenciones de la empresa en el espacio urbano. También se valorará la forma en la que el anhelo de mayores derechos y competencias mostrado desde la corporación local determinó enfrentamientos de primera magnitud con la mencionada empresa y autoridades gubernamentales.
\end{abstract}

PALABRAS CLAVE: Madrid, transportes urbanos, ferrocarril metropolitano, política municipal.

ABSTRACT: This article analyses the construction and the initial development of the subway system in Madrid, through the research of the conflicts of legal and political interest that arose between the three organisations involved in it. Firstly, the municipal government of the city; secondly, the concessionary company of the new transport; and finally, the Spanish government. The aim of this paper is to understand the position that the City Council showed in a very specific context of effervescence of municipal action, characterised by claims of wider attributions in the management of urban services. In order to fulfil this purpose, we will addressed not only the claims against the transport company exposed by the main municipal deputies. It will also be valued the way in which the desire for wider rights and competences shown by the local corporation determined very significant confrontations with the aforementioned company and with the government authorities.

KEYWORDS: Madrid; urban transportation; underground railway system; urban politics.

* Correspondencia a: Santiago de Miguel Salanova. Universidad Complutense de Madrid, Departamento de Historia Moderna e Historia Contemporánea, Facultad de Geografía e Historia, Edificio B. Calle Profesor Aranguren, s/n. 28040 Madrid (Spain) - sdmiguel@ghis.ucm.es - https://orcid.org/0000-0003-1392-0925

Cómo citar: Miguel Salanova, Santiago de (2020). "La batalla del Metropolitano. Protesta municipal y conflicto político en Madrid a finales de la Restauración»; Historia Contemporánea, 64, 809-840. (https://doi.org/10.1387/hc.20490).

Recibido: 27 diciembre, 2018; aceptado: 15 febrero, 2019.

ISSN 1130-2402 - eISSN 2340-0277 / (C) 2020 UPV/EHU

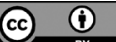

Esta obra está bajo una licencia

Creative Commons Atribución 4.0 Internacional 


\section{Introducción}

El 12 de enero de 1917 representa una fecha decisiva en la historia de los transportes públicos de Madrid. El Ministerio de Fomento emitió entonces veredicto favorable sobre la iniciativa presentada en mayo de 1914 por los ingenieros Antonio González Echarte, Carlos Mendoza y Miguel Otamendi, bajo la denominación de «Metropolitano de Madrid». Se trataba de un ferrocarril subterráneo, con tracción eléctrica, de servicio particular y uso público, solicitado sin subvención ni garantía de interés por el Estado y compuesto por cuatro líneas (Cuatro Caminos-Plaza del Progreso; Calle de Ferraz-Calle de Goya previo paso por Puerta del Sol y Calle de Alcalá; Calle de Serrano-Diego de León; y Ferraz-Goya por los bulevares). Su principal objetivo era resolver el problema de la circulación en una ciudad que superaba los 600.000 habitantes.

Madrid era una urbe que se hallaba todavía muy lejos del volumen poblacional de otras ciudades en las que se había implantado el Metro con anterioridad. Sin embargo, lo necesitaba por sus características estructurales. La movilidad de su vecindario venía dificultada por la angostura de sus calles y su escasa capacidad para el tránsito rodado, sobre todo en el casco antiguo ${ }^{1}$. En espera de la urbanización de la Gran Vía, esa zona demostraba su insolvencia para seguir actuando como punto de convergencia del movimiento circulatorio de peatones y carruajes y corazón del que partían las arterias de una compleja red de tranvías ${ }^{2}$. Al mismo tiempo, existía la inaplazable necesidad de conectar el anterior entorno con el extrarradio ${ }^{3}$. Aquí debe valorarse la notable densidad poblacional que la segunda zona advirtió con el proceso de improvisada absorción residencial en el que se embarcó desde finales del ochocientos, agotada la idea del Ensanche tal y como se planteó en $1860^{4}$. Y finalmente, el futuro transporte podía atenuar el problema del paro forzoso y el residencial en el complejo marco de la Primera Guerra Mundial, abriendo oportunidades para una remodelación del mercado laboral y para el asentamiento poblacional en espacios distantes de un centro cada vez más encarecido ${ }^{5}$.

\footnotetext{
1 Ruiz Palomeque, 1976; De Miguel, 2017.

2 López Bustos, 1998; Gutiérrez, 2001; Martínez, 2002,pp. 149-179.

3 Vörms, 2012.

4 Carballo, Pallol y Vicente, 2008.

5 Sánchez Pérez, 2005.
} 
La mayoría de estudios relacionados con la evolución del Metro de Madrid han incidido en los aspectos señalados. Algunos de los más interesantes dialogan con las transformaciones económicas y sociales experimentadas por la capital española en el primer tercio del novecientos y permiten comprender las causas que motivaron la aparición del citado transporte ${ }^{6}$. Otros se han detenido en el desarrollo económico de la compañía que lo construyó y explotó, en la influencia que tuvo a largo plazo para el desarrollo de la ciudad, en sus características arquitectónicas o en los proyectos nonatos que antecedieron al aprobado ${ }^{7}$. Junto a ellos, cabe destacar finalmente una serie de trabajos que han abordado la historia del Metro en un marco de entendimiento con la evolución de otros transportes públicos como los tranvías, para descubrir las dinámicas de competitividad que surgieron entre ellos ${ }^{8}$.

El corpus bibliográfico vinculado a la trayectoria de otros ferrocarriles metropolitanos extranjeros también ha estado mayoritariamente asociado a las temáticas apuntadas para Madrid. Han sido profusos los estudios sobre la evolución de este transporte en Londres, París o Nueva York, planteando enfoques narrativos y cronológicos asociados a su construcción y a su contribución al desarrollo de un planeamiento urbanístico racional que terminaría consolidando su estatus de metrópolis modernas ${ }^{9}$. Sin embargo, en algunos de ellos es posible detectar una profundización analítica en cuestiones no valoradas para el caso que nos concierne, como las implicaciones que el Metro tuvo en la creación de nuevas identidades y en las percepciones del espacio público entre los habitantes de las ciudades ${ }^{10}$; en las dinámicas de reconfiguración espacial y usos del suelo ${ }^{11}$; o en la aparición de estrategias de control y racionalización de las nuevas experiencias sociales a las que dio cabida su utilización ${ }^{12}$.

En un contexto caracterizado por la difusión de una tecnología que abrió paso al advenimiento de procesos de homogeneización y estanda-

\footnotetext{
${ }^{6}$ Rodríguez, 2015, pp. 115-156.

7 Méndez, 2000; Matilla y Frax, 2003, pp. 81-99; González Yanci, 2006; Moya, 2009; Zamorano, 2012; Ruiz Zapatero, 2015; Olivares, 2015.

8 López Gómez, 1983; Matilla, Polo y Benegas, 2002; Delgado, 2010.

9 Para Londres, véanse: Barker y Robbins, 1974; Day y Reed, 2001; Halliday, 2001. Para París: Evenson, 1979; Hallsted, 1997; Larroque, Margairaz y Zembri, 2002. Para Nueva York: Cudahy, 1988; Hood, 1995; Derrick, 2001 y Raskin, 2014.

10 Hood, 1996, pp. 308-331; Hallsted, 1999; Williams, 2008.

11 Bradley, 2006; King, 2011, pp. 19-32; Darroch, 2014, pp. 105-116.

12 Höhne, 2015, pp. 313-321.
} 
rización de espacios y prácticas de movilidad intraurbana, surgieron también tensiones en lo que respectaba a la forma de concebir el ferrocarril subterráneo que tampoco ha obviado la historiografía internacional. Paradigmático es el caso de París, que vislumbró en los decenios previos al comienzo de las obras del Metro un largo debate entre el Gobierno y el Ayuntamiento de la ciudad a la hora de dirimir la titularidad del transporte. Aquel tuvo su inicio a partir del 11 de junio de 1880, fecha en la que se aprobó una ley reconociendo a los municipios franceses su capacidad de gestionar las líneas ferroviarias que circulasen en sus términos. Este estatus parecía aplicarse inequívocamente al futuro Metro, valorándolo como un sistema de tránsito para los barrios del interior de París. Sin embargo, el Parlamento no tardó en diferir de esa consideración. En 1883 se opuso frontalmente al proyecto de ferrocarril metropolitano planteado por el ingeniero Frédéric Soulié, aduciendo que era de interés nacional y sometido, en consecuencia, al arbitraje estatal.

Desde ese momento se abrió un conflicto de intereses en torno a la cuestión del Metro en el que participaron dos frentes. El primero, encabezado por el Gobierno, defendió una perspectiva globalizadora para el transporte, conectado con el resto del país por las grandes estaciones ferroviarias de la ciudad. El segundo, comandado por el Ayuntamiento, se amparaba en la citada ley de 1880 para considerar las pretensiones estatales como una injerencia en sus competencias. De manera paralela a este proceso, se fueron escenificando las discrepancias políticas existentes entre la opción republicana más conservadora de un Parlamento que buscaba garantizar el sometimiento de París a la esfera de poder estatal y la opción republicana social de la capital, representada por un consistorio que defendía su autonomía en la gestión de cualquier servicio de utilidad pública local ${ }^{13}$. En el marco de esa pugna, el reconocimiento final de la competencia del Ayuntamiento sobre el Metro tuvo una enorme importancia simbólica, pues su construcción y financiación fue, para la institución local, una elocuente forma de reconocer su autoridad sobre los asuntos que entendía como propios en el ámbito urbano.

Al igual que en París, el Metro también se convirtió en un motivo de disputa entre el Estado y el Ayuntamiento para el caso de Madrid. El segundo organismo planteó una campaña de oposición con respecto a las condiciones de implantación del nuevo transporte que fue creciendo hasta

13 Desabres, 2003; Cottereau, 2004, pp. 89-151. 
culminar en un enfrentamiento entre sus cargos representativos y las fuerzas de seguridad gubernamentales. Para el consistorio de la capital española, esa lucha tuvo un sentido claro muy similar al de la capital francesa: la defensa de mayores competencias frente a las injerencias estatales.

La posición del Ayuntamiento en el conflicto del Metro entre 1917 y 1922 solo puede entenderse si previamente se valora la efervescencia que la acción política municipal mostró durante esa etapa en $\mathrm{Madrid}^{14}$. En esa coyuntura, caracterizada además por una notable conflictividad económica y social y por una fuerte politización ciudadana, el gobierno local estaba siendo objeto de una reconceptualización. Comenzaba a ganar fuerza la idea de que necesitaba tanto alcaldes y concejales capaces de desarrollar políticas lógicas que encajaran con los problemas de la evolución urbana como una determinación más amplia de sus cometidos. A ojos de las fuerzas políticas apartadas del turnismo de la Restauración, debía ser una entidad facultada para actuar en cuanto redundara en provecho de la comunidad y no simplemente una pieza al servicio de la maquinaria estatal. En consecuencia, todos los servicios que afectaran al bienestar del vecindario no podían escapar de las fronteras de sus competencias. Y desde luego, aquellos debían sustraerse a la esfera mercantil tradicionalmente amparada por el Estado, esto es, a las compañías privadas que los ejecutaban como concesionarios. Bajo la influencia de las tesis municipalistas que llegaban de otros países, fue permeando la concepción de que esas empresas otorgaban dichos servicios sin desarrollar un verdadero sentido de responsabilidad con los intereses de la ciudad y sus habitantes ${ }^{15}$.

Estas consideraciones estuvieron presentes en los debates desarrollados en el Ayuntamiento de Madrid durante la etapa estudiada, y principalmente en los relativos a los transportes. Pudo comprobarse claramente en el caso del Metro aquí analizado, pero también en la política tranviaria en este mismo contexto. A partir de la segunda década del novecientos se cuestionó desde el consistorio su naturaleza, basada en una centralización vehiculada por la Ley General de Ferrocarriles de 1877. Con esta se proclamó la competencia estatal sobre los tranvías, dejándose en adelante su gestión en manos de concesionarios privados ${ }^{16}$. El consistorio madrileño, que asumió con esa normativa funciones secundarias de inspección y vigilancia, la terminaría entendiendo como una injerencia gubernamental en

14 De Miguel, 2019.

15 Magaldi, 2012.

16 Armengol, 2012, pp. 9-11. 
las atribuciones que entendía como legítimas sobre las vías públicas. A partir de 1913, reivindicaría con fuerza un viraje en la ejecución del servicio, que consideraba oneroso socialmente hablando y deficiente ${ }^{17}$, y la adquisición de mayores competencias en su desarrollo y gestión, en detrimento de la empresa concesionaria y del Estado. Demandas similares a estas últimas se apreciarían, como veremos, durante la construcción del ferrocarril metropolitano.

Teniendo en cuenta estas premisas introductorias, este artículo profundizará en las causas y características del conflicto del Metro mediante la utilización de diversas fuentes primarias (expedientes relacionados con el Metropolitano del Archivo Histórico Nacional y del Archivo de Villa de Madrid, libros de actas del Ayuntamiento de Madrid, documentación del Archivo de Metro de Madrid y publicaciones periódicas). En todos los análisis debe entenderse como fundamental el contexto en el que se desarrolló el pleito, clave para explicar las demandas de mayores competencias por parte del gobierno municipal en la ejecución de planes y estrategias que permitieran acompasar la evolución de la institución con la que observaba la urbe a nivel demográfico, económico y social.

\section{Los orígenes jurídicos de la cuestión del Metropolitano de Madrid}

El Ayuntamiento de Madrid fue desde un primer momento consciente de las ventajas que deparaba para la ciudad la construcción del Metro. Suscribía los objetivos del proyecto, entendiendo que coadyuvarían en la modernización urbana cubriendo los vacíos no rellenados por los tranvías en las nuevas dinámicas circulatorias ${ }^{18}$. Sin embargo, también advirtió desde el principio dificultades en su ejecución. Su principal objeción al transporte residía en la consideración que se hizo del mismo en la concesión del Ministerio de Fomento del 12 de enero de 1917. Su expediente se tramitó de acuerdo con la Ley de Ferrocarriles Secundarios de 23 de febrero de 1912, que entendía como tales «los destinados al servicio público con motor mecánico de cualquier clase que se concedan en adelante y no estén comprendidos en la red de los de servicio general» (artículo 1). En esa normativa se fijaban los plazos de reversión para las concesiones de

17 Sánchez Pérez, 2005 y Rodríguez, 2015, pp. 118-128.

18 Archivo de Villa de Madrid (AVM), Libro de Actas del Ayuntamiento de Madrid (LAAM), sesión del 19 de enero de 1917. 
estos transportes en noventa y nueve años (a favor del Estado) y las funciones a cumplir por el Gobierno en su construcción y explotación (asegurar la solidez y estabilidad de las obras e inspeccionarlas en las debidas condiciones de seguridad, higiene y comodidad).

Para el consistorio madrileño, el Metropolitano era, por su funcionalidad, un medio de transporte equiparable a los tranvías. Estos estaban sometidos a la Ley General de Ferrocarriles de 23 de noviembre de 1877 y al Reglamento dictado el 24 de mayo de 1878 para su ejecución. En función de las disposiciones ahí contenidas, tenían un plazo de concesión más reducido que el del Metropolitano (sesenta años) y reconocían derechos a la corporación local en la vigilancia, inspección facultativa y reversión de sus líneas ${ }^{19}$. Lo anteriormente señalado sirve para explicar las razones por las que en el recurso contencioso-administrativo interpuesto contra la concesión del Metropolitano por el Ayuntamiento de Madrid el 13 de enero de 1917 se definió la Ley de Ferrocarriles Secundarios como «el más patente y deplorable ejemplo» de las deficiencias presentadas por las normativas ferroviarias a nivel nacional. A juicio de los concejales, aquellas privaban a los municipios de la participación que debían tener en el régimen y funcionamiento de un medio de transporte establecido en sus límites espaciales ${ }^{20}$.

Para el Ayuntamiento de Madrid, la concesión también evidenciaba un nulo respeto de facultades que entendía como de su exclusiva competencia, con arreglo al artículo 72 de la Ley Municipal de 1877. Así se advertía en lo relacionado con el arreglo y cuidado de las vías públicas a las que habrían de afectar las obras del ferrocarril subterráneo y su explotación, pero también en lo que respectaba a la comodidad e higiene del vecindario, al fomento de su seguridad y a la policía urbana. El consistorio consideraba que las garantías que se le concedían en estos apartados eran insuficientes. El concesionario de las obras del Metropolitano únicamente estaba obligado a escuchar la opinión de los inspectores facultativos municipales a la hora de establecer «estaciones, apeadores o apartaderos» y a ejecutar todas las obras que fueran necesarias para que las calles no sufrieran «desperfectos ni entorpecimientos, empleando materiales de la

19 AVM, LAAM, sesión ordinaria del 19 de enero de 1917.

20 Archivo Histórico Nacional (AHN), FC-TRIBUNAL_SUPREMO_RECURSOS, 158, Exp. 991. Recurso n. ${ }^{\circ}$ 991/1917 del Ayuntamiento de Madrid contra la Real Orden del Ministerio de Fomento sobre concesión de un ferrocarril subterráneo denominado «Metropolitano de Madrid»(1917-1920). 
misma clase, condiciones y dimensiones que los que en las vías públicas correspondientes utilizasen los encargados de su conservación» ${ }^{21}$. La corporación local exigía una amplificación de estos términos para ostentar lo que creía era su legítimo derecho: conocer con detalle todo lo relacionado con la construcción y explotación del Metro.

Finalmente, el concejo madrileño consideraba que, incluso en el hipotético caso de llegar a contemplar la concesión del nuevo transporte como aplicable a la Ley de Ferrocarriles Secundarios, se cometían infracciones legales que no se podían obviar. Las líneas proyectadas para aquel debían establecerse en el subsuelo de las vías públicas de Madrid, el cual entendía el consistorio de su propiedad según lo dispuesto en los artículos 344 y 350 del Código Civil de 1889. El primero reconocía los caminos provinciales y vecinales, plazas, calles, fuentes y paseos como bienes patrimoniales de los municipios de uso público. El segundo consignaba que el propietario de un terreno como los señalados era dueño «de su superficie y de lo que está debajo de ella», pudiendo hacer en él las obras, plantaciones y excavaciones que le convinieran ${ }^{22}$.

Para la representación municipal, la concesión del Ministerio de Fomento carecía además de las formalidades que se requerían al ocupar terrenos pertenecientes al dominio corporativo. No exigía ni consideraba la expropiación forzosa de aquellos por causa de utilidad pública (de acuerdo con la ley de 10 de enero de 1879) y tampoco el pago de un canon a su legítimo dueño por su utilización. Lo que todo esto provocaba era muy claro. El concesionario de las obras gozaría gratuitamente de una propiedad municipal con la posibilidad añadida de transferir a un tercero el derecho que se le reconocía, sin que el Ayuntamiento percibiera cantidad económica o manifestara previamente su autorización.

Las reacciones a esta postura del consistorio no se hicieron esperar ${ }^{23}$. La compañía del Metropolitano descartó sus reclamaciones, comenzando con la equiparación de los ferrocarriles subterráneos a los tranvías. No se establecían los primeros sobre calles construidas de antemano para usos públicos, sino debajo de las mismas y en explanaciones hechas ad hoc. Estas precisiones eran fundamentales, ya que llevaban al Metropolitano a no encajar en las definiciones de la Ley General de Ferrocarriles de 1877. Teniendo en cuenta que el proyectado ferrocarril subterráneo no era una

\footnotetext{
${ }^{21}$ Ibid.

${ }_{22}$ Gaceta de Madrid, 25 de julio de 1889, pp. 249-259.

23 AHN, FC-TRIBUNAL_SUPREMO_RECURSOS, 158, Exp. 991, 1917.
} 
línea complementaria de las que se establecieron en ese plan, que no se destinaba a la explotación de usos privados y que tampoco se acoplaba a la definición de estratégico, no cabía para aquel otra clasificación que la de secundario.

Relevantes fueron también los matices establecidos por la compañía con respecto a la propiedad del subsuelo. Entendía que los terrenos a ocupar en la ciudad no eran del consistorio, sino «dominio eminente del Estado». El Código Civil en el que se amparaban las instancias municipales para aludir a este apartado limitaba los derechos del propietario del suelo, entendiendo como tal la superficie y lo que estaba debajo de ella, oponiéndose frontalmente al artículo 52 de la Ley de Minas, que especificaba que el subsuelo era de dominio estatal. El artículo 344 de aquel corpus dividía los bienes de los municipios en generales de uso público (calles, plazas, etc) y patrimoniales que podían ser, a su vez, de uso común y de propios. En función de lo que ahí se estipulaba, el Ayuntamiento no estaba en condiciones de alegar que las calles fuesen de su propiedad para así aplicarlas el precepto sobre la propiedad corporativa de la Ley de Ferrocarriles Secundarios ${ }^{24}$.

El Ministerio de Fomento también reaccionó negativamente a la postura del Ayuntamiento de Madrid ratificando la concesión mediante una nueva Real Orden el 26 de enero de 1917. Por ella, solo se declaraba como procedente la reclamación por la que aquel solicitaba el derecho de examinar y emitir interpretaciones que debían ser escuchadas por la compañía concesionaria del Metropolitano en lo relacionado con los planos y perfiles del replanteo de las líneas proyectadas y con las obras especiales que se exigieran en lo sucesivo (relacionadas con el alcantarillado y con el Canal de Isabel II).

Sobre la base de estas respuestas y guiado por las interpretaciones que sobre la cuestión del Metropolitano hicieron sus ediles y alcaldes, el consistorio tomó el 20 de abril de 1917 la decisión de no oponer dificultades a la realización de las obras del transporte, sosteniendo, al mismo tiempo, cuanto se reivindicaba en el recurso contencioso-administrativo interpuesto al Tribunal Supremo en espera de una resolución ${ }^{25}$. El consistorio no desistió de la posibilidad de emprender acciones contra la empresa concesionaria de las obras. Simplemente, renunció a un procedimiento

24 AHN, FC-TRIBUNAL_SUPREMO_RECURSOS, 158, Exp. 991, 1917-1920.

25 AVM, LAAM, sesión del 20 de abril de 1917. 
más rápido para la solución del pleito basado en el interdicto, al entender que no debían paralizarse obras «beneficiosas para la capital» ${ }^{26}$. Esta pugna entre el anhelo del transporte y la crítica de las condiciones en que se otorgaba estaría permanentemente presente en la corporación local en los meses que transcurrieron entre la concesión del Ministerio de Fomento y el comienzo de las obras, agravándose posteriormente con la definitiva sentencia del Metro del Tribunal Supremo del 13 de mayo de 1920.

\section{El Ayuntamiento de Madrid y la defensa de sus competencias municipales durante las obras del nuevo transporte urbano}

Los primeros trabajos relativos al Metropolitano de Madrid se iniciaron el 23 de abril de 1917. Las publicaciones de las siguientes jornadas insistieron en la trascendencia del proyecto e hicieron reseñas sobre las características de este medio de transporte en Londres, París o Nueva York, consignando sus beneficiosas aplicaciones al de $\mathrm{Madrid}^{27}$. Algunos sectores se mostraron escépticos, dudando del cumplimiento de los plazos fijados por la compañía para la apertura del primer tramo entre las estaciones de Cuatro Caminos y Puerta del Sol (octubre). Sin embargo, la opinión pública manifestó un optimismo generalizado con respecto a este asunto.

Quien más apartó de esa opinión fue el Ayuntamiento de Madrid, fijando el epicentro de sus reclamaciones en lo que ocurría en la Puerta del Sol. Nada más iniciarse los primeros trabajos en la plaza, se emitieron desde el organismo algunas protestas por los perjuicios que la empresa del Metropolitano ocasionaba para el tránsito en esa zona ${ }^{28}$. La valla que allí se instaló para informar de los plazos del cumplimiento de las obras, así como los evacuatorios y quioscos transformadores de electricidad fijados entre la calle de Alcalá y la carrera de San Jerónimo, se entendieron como obstáculos para la movilidad. Se llegó incluso a plantear una alternativa al establecimiento de la estación central en la Puerta del Sol, que sería la Plaza de Pontejos, situada a 100 metros de distancia ${ }^{29}$. Sin embargo, la

26 Ibid.

27 El Imparcial, 2 y 8 de mayo de 1917.

28 AVM, LAAM, sesión del 18 de mayo de 1917.

29 AVM, Secretaría (AVM-S), Expediente promovido a moción del concejal Sr. Crespo interesando que la estación central de la Puerta del Sol se instale en la Plaza de Pontejos (1917), 49-359-1. 
compañía concesionaria se opuso rotundamente a esa modificación y la Dirección General de Obras Públicas resolvió el caso a su favor ${ }^{30}$.

También en ese contexto inicial, el jefe de las obras del pavimento y subsuelo de Madrid, Pedro Núñez Granés, informó al consistorio de una serie de deficiencias relacionadas con los emplazamientos que la empresa había seleccionado para la construcción de las escalinatas de bajada a la futura estación de Sol. A su juicio, generarían dificultades para un tránsito que ya entonces se realizaba «en malísimas condiciones» y que empeoraría en el futuro. El ingeniero también plantearía al Ayuntamiento la conveniencia de conseguir que los viajeros, al salir de los ascensores instalados en la estación central, «no tuvieran que subir los peldaños correspondientes a los cuatro o cinco metros que, como mínimo, habría de tener de altura el vestíbulo que para poder alojarles habría de construirse en el subsuelo». Para lograr esto se ofrecía una alternativa, finalmente no valorada, consistente en seleccionar «un local cualquiera de los edificios existentes en la Puerta del Sol que quedara para la instalación de los ascensores». De esta manera, no se pondrían nuevos obstáculos en un espacio tan transitado $^{31}$.

Si las anteriores consideraciones se relacionaban con los problemas que la apertura de la primera línea del Metropolitano planteaba para la circulación en la Puerta del Sol, las presentadas a comienzos de 1919 se vincularían con las consecuencias que las obras generaban en la superficie de esta zona. Fue el teniente de alcalde del distrito del Centro, José Gabilán, quien expresó su mayor preocupación sobre este tema ${ }^{32}$. A comienzos de enero evidenció depresiones en el pavimento de la plaza que amenazaban con ocasionar «hundimientos de graves repercusiones». Sus tareas de fiscalización le llevaron a comunicar a la alcaldía la necesidad de prohibir la circulación de peatones, tranvías y carruajes en el espacio afectado. Los técnicos encargados de las inspecciones de fontanería y alcantarillas del Ayuntamiento de Madrid fueron inmediatamente consultados por el alcalde e informaron de que en la Puerta del Sol se practicaban reconoci-

30 AVM, LAAM, sesión del 24 de agosto de 1917.

31 AVM-S, Expediente promovido a virtud de oficio del ingeniero jefe de las obras del pavimento y subsuelo de Madrid, D. Pedro Núñez Granés, remitiendo los planes de replanteo de la línea 1 (1917), 49-359-13.

32 AVM-S, Expediente a oficio del teniente de alcalde del distrito del Centro, D. José Gabilán, indicando la necesidad de que se ponga en conocimiento de la inspección del Estado las depresiones observadas en el pavimento de la Puerta del Sol (1919), 57-112-15. 
mientos diarios del pavimento dentro del perímetro que ocupaba la estación y seguimientos de las alteraciones presentadas en la superficie y en los servicios del subsuelo. Entendieron los movimientos del terreno como una consecuencia lógica de las obras y juzgaron que la lentitud con la que se producían evitaría los posibles accidentes a los que se refirió Gabilán. No obstante, sí aconsejaron adoptar precauciones extremas en la plaza. Era conveniente que la empresa levantara el pavimento en la parte que presentaba depresiones y que restableciera la rasante de la vía del tranvía y del asfalto $^{33}$. Los informes elaborados sobre este tema fueron inicialmente aceptados por Otamendi. Sin embargo, los nuevos desniveles observados a comienzos de 1922 evidenciaron un escaso seguimiento de los mismos por parte de la compañía ${ }^{34}$.

Las irregularidades que el consistorio detectó en la realización de las obras en la Puerta del Sol se extendieron a otros enclaves afectados por la apertura de la primera línea del Metro. Algunas estuvieron nuevamente relacionadas con amenazas de hundimientos. Así ocurrió en la calle de Luchana en agosto de 1917 y con posterioridad en la Glorieta de Bilbao (noviembre de 1917) ${ }^{35}$. Para las autoridades municipales, esos siniestros respondían a imperfecciones técnicas cometidas por la compañía del Metropolitano durante las obras. Estas se asociaron a las interferencias de sus trabajos con otros servicios del subsuelo (gas y agua), a la carencia de medidas de previsión laboral y a la ausencia de condiciones de solidez en la construcción de las bóvedas de los túneles ${ }^{36}$. El consistorio envió comunicaciones al Ministerio de Fomento, buscando mayores facultades inspectoras para sus técnicos municipales. Sin embargo, estas llamadas no tuvieron una respuesta positiva. Otamendi, por su parte, negó siempre cualquier responsabilidad para la empresa, expresándose en los siguientes términos:

«En las obras de un metropolitano todo está calculado y medido y los agujeros no pueden por menos de hacerse por donde realmente deben ir (...). Puede suceder, y sucede en efecto, que se rompan cables y cañerías de las conducciones subterráneas. Unas veces es un golpe

33 El Liberal, 11 de enero de 1919 y El Heraldo de Madrid, 14 de enero de 1919.

34 AVM, LAAM, sesiones del 25 de febrero y 1 de marzo de 1922.

35 El Debate, 13 de agosto de 1917 y La Correspondencia de España, 15 de noviembre de 1917.

36 AVM, LAAM, sesiones del 8 de marzo de 1918 y 1 de mayo de 1920. 
de pico que agujerea o corta una de estas cañerías o uno de estos cables; otras, las más, obedece a lo siguiente: la tierra con que se tapa una zanja, por bien que quiera apisonarse, tarda bastante (un año o así) en hacer asiento (...). Este accidente es corregido rápidamente y, además, es inevitable por mucho examen que quiera ponerse en la obra.» ${ }^{37}$

Como vemos, el Ayuntamiento de Madrid buscó desde un principio introducir cambios en los procedimientos técnicos de las obras del Metropolitano para adecuarlos a las necesidades urbanas. Sin embargo, sus posibilidades de conseguirlo eran mínimas mientras el Tribunal Supremo no resolviera a su favor el recurso contencioso-administrativo presentado en enero de 1917. La espera culminaría con la sentencia del 13 de mayo de 1920. Esta última revocó la actuación del Ministerio de Fomento y consideró que, si bien la modalidad de los ferrocarriles metropolitanos no había sido objeto de disposiciones especiales, se ajustaba mejor con lo dispuesto en el artículo 1 en la Ley de Ferrocarriles Secundarios de 1912. El Tribunal Supremo se declaró incompetente de jurisdicción para resolver en lo concerniente a la propiedad del subsuelo, si bien alegó los preceptos de la Ley de Minas para definirlo como «dominio eminente del Estado» ${ }^{38}$.

En un primer momento, el consistorio reaccionó a esas disposiciones emprendiendo nuevas inspecciones secundarias para valorar el grado de respeto que la empresa concesionaria del transporte mostraba hacia las ordenanzas municipales en los trabajos que desarrollaba. Uno de los puntos más relevantes en este escenario fue el relacionado con la apertura de calas y zanjas en las vías públicas de la ciudad, para lo cual el gobierno municipal creó un reglamento especial en agosto de $1917^{39}$. Este tenía un apartado específicamente dirigido a la compañía concesionaria del nuevo transporte, la cual debía proveerse de volantes para las calas, zanjas y pozos abiertos en cada calle en la que interviniera, solicitándolos de antemano a la alcaldía. Paralelamente, tendría que respetar disposiciones relativas a la colocación de vallas y carteles informativos de las obras en los espacios en los que se operaba, a la limpieza de los materiales y herra-

37 El Sol, 30 de enero de 1918.

38 AHN, FC-TRIBUNAL_SUPREMO_RECURSOS, 158, Exp. 991, 1917-1920.

39 AVM-S, Expediente a moción de la alcaldía regulando la apertura de calas en las vías públicas de Madrid (1917), 20-363-38 y AVM-S, Expediente promovido a virtud de oficio de la alcaldía-presidencia a la gerencia del Ferrocarril Metropolitano Alfonso XIII, ordenándole las reglas a las que debía sujetarse en las obras emprendidas (1917), 49359-6. 
mientas que quedaran en las vías una vez concluida la jornada laboral y a la instalación de faroles para señalizar las zonas de trabajo, garantizando la seguridad de los viandantes.

Tras declararse la competencia estatal sobre el Metro, las quejas del consistorio sobre el incumplimiento de los puntos del anterior reglamento por parte de la compañía se hicieron sistemáticas. Relevantes fueron las emitidas sobre el estado de las calles de Luchana y Santa Engracia. Allí se produjeron accidentes de cierta relevancia entre el vecindario por la ausencia de faroles de luz en los enclaves donde se realizaban las obras y de vallas en los alrededores de algunos pozos y zanjas abiertos en las vías. Posteriormente se detectaron en la Plaza del Progreso, donde la compañía valló un amplio espacio acotando parte de sus jardines; en la calle de la Magdalena, donde los vecinos denunciaron amontonamientos de tierras y agrietamiento de las aceras; y en la calle del Pacífico, donde se talaron ochenta árboles sin licencia municipa $\mathrm{l}^{40}$.

El Ayuntamiento de Madrid impuso numerosas multas en virtud de lo dispuesto en el capítulo V de las Ordenanzas Municipales de 1892 y en la Ley Municipal de $1877^{41}$. Sin embargo, todas fueron recurridas por la compañía del Metropolitano ${ }^{42}$. A juicio de Otamendi, las condiciones de la concesión del ferrocarril subterráneo exponían con claridad que correspondía al Cuerpo de Ingenieros de Caminos dependiente del Estado la inspección de las obras de la empresa tanto en el suelo como en el subsuelo, así como cuidar de que no se interrumpiera el tránsito público. Asimismo,

40 AVM, LAAM, sesiones del 8 de julio de 1920 y del 29 de abril y 10 de junio de 1921 y AVM-S, Expediente incoado a virtud de comunicación del jardinero mayor del Ayuntamiento de Madrid denunciando la corta de árboles por la Compañía del Metropolitano en la calle del Pacífico (1922), 49-359-24.

${ }^{41}$ Las sanciones económicas se imponían de acuerdo con la Ley Municipal de 1877, que en su artículo 77 precisaba: «Las penas que por infracción de las Ordenanzas y reglamentos impongan los Ayuntamientos sólo pueden ser multas que no excedan de 50 pesetas en las capitales de provincia, 25 en las de partido judicial y pueblos de 4.000 habitantes y 15 en las restantes, con el resarcimiento del daño causado e indemnización de gastos». Algunos ejemplos de estas sanciones en: AVM-S, Multas impuestas por el Ayuntamiento de Madrid a la Compañía del Metropolitano Alfonso XIII, 1922, 24-125 (12-13-14).

42 AVM-S, Expediente a virtud de instancia del director de la Compañía del Metropolitano Alfonso XIII interponiendo recurso de alzada contra la imposición de una multa fijada por el Teniente de Alcalde del distrito de la Universidad (1920), 57-112-6; AVM-S, Expediente a virtud de recurso interpuesto por la Compañía del Metropolitano Alfonso XIII contra multa impuesta por el teniente de alcalde del distrito del Centro (1922), 49-359-40. 
entendía que, incluso en el caso hipotético de que se reconocieran competencias en esta materia al consistorio, de esas multas únicamente podría responsabilizarse a los infractores directos de las disposiciones de Policía Urbana, esto es, a los obreros contratados por la compañía ${ }^{43}$.

De manera paralela, las reclamaciones del Ayuntamiento con respecto a las actuaciones de la compañía del Metropolitano se extrapolaron a otros ámbitos. Se denunció la escasa regularidad con la que circulaban sus trenes, el incumplimiento de sus horarios de salida y las interrupciones en el movimiento entre estaciones. De igual forma, se protestó por la nula información que se difundía a los usuarios sobre estos percances. Así lo hizo el concejal socialista Andrés Saborit, solicitando que desde el Gobierno Civil se obligara a la empresa a poner a disposición de los usuarios libros de reclamaciones, inspectores que atendieran sus quejas y avisos con indicación de las horas de llegada de los trenes y de los retrasos que presentaran, debidamente justificados ${ }^{44}$. Finalmente, se clamó contra la libertad de la empresa en la fijación de tarifas. Especialmente problemática fue la situación presentada en enero de 1922, coincidiendo con la apertura del tramo Sol-Atocha. La compañía estableció entonces nuevos precios para los billetes sencillos, que pasaban a aumentar conforme lo hacía el número de estaciones recorridas por los viajeros, siendo el coste mínimo de quince céntimos y el máximo de treinta. Las protestas se contaron por centenares, alegándose en ellas falta de transparencia de la compañía a la hora de informar sobre los incrementos ${ }^{45}$. Para los concejales, lo más grave de este caso fue el incumplimiento de los precios inicialmente prometidos, alejados del formato único de otros metros europeos y carentes de descuentos para la clase obrera ${ }^{46}$.

En esta creciente oposición del consistorio a la compañía del Metropolitano no sólo estaba incidiendo la ya mencionada sentencia del Tribunal Supremo. También tuvo una influencia decisiva el contexto en el que aquella salió a la luz, poco después del cierto grado de autonomía que se había reconocido para el gobierno municipal a finales de 1918, permitiéndose que sus alcaldías y tenencias de alcaldía fueran votadas por los con-

43 AVM-S, Recurso de alzada ante el Sr. Gobernador Civil de la Provincia de Madrid contra seis multas impuestas por la alcaldía de Madrid a la Compañía del Metropolitano Alfonso XIII (1922), 24-125-15.

44 AVM, LAAM, sesión ordinaria del 15 de enero de 1922.

45 El Imparcial, La Voz y El Heraldo de Madrid, 18 al 22 de enero de 1922.

46 AVM, LAAM, sesiones del 10 de junio de 1921 y 20 de enero de 1922. 
cejales elegidos en las urnas y no designadas por Reales Órdenes del Ministerio de Gobernación como hasta entonces. Se inauguraron con ello unas cotas de mayor democracia en el Ayuntamiento que facilitaron una conducta más reivindicativa entre sus representantes, particularmente contra aquellas empresas que gestionaban asuntos que se entendían que eran propios de la Municipalidad, como la del Metropolitano ${ }^{47}$. El pleito con la compañía se amplificó en ese marco, hasta entenderse que la única solución para el mismo pasaba por la promulgación de una ley específica que diera al consistorio intervención oficial en las obras y tareas de explotación del transporte ${ }^{48}$.

\section{Barcelona como modelo a seguir. Intensificación de las presiones del gobierno municipal de Madrid sobre la Compañía del Metropolitano}

Las discordancias entre el Ayuntamiento de Madrid y la compañía del Metropolitano se agravaron de manera inexorable con las noticias que llegaron desde Barcelona en 1921. El 12 de febrero de ese año se otorgó, mediante Real Orden del Ministerio de Fomento, la concesión de un ferrocarril subterráneo eléctrico en la capital catalana a un grupo formado por el Banco de Vizcaya, el Banco Hispano Colonial, la Sociedad Anónima Arnús-Gari, la empresa de tranvías de Barcelona y los ferrocarriles de Cataluña. El objetivo era unir las barriadas de Gracia y Sant Gervasi con el puerto, pasando por el Paseo de Gracia y la Plaza de Cataluña ${ }^{49}$.

La necesidad de este medio de transporte era clara, teniendo en cuenta el desarrollo de la ciudad y la relevancia alcanzada en términos demográficos por las zonas señaladas, originando un flujo de pasajeros que los tranvías no podían asumir. Estas apreciaciones ya estaban presentes en la mente de los ingenieros Pablo Muller y Octavio Zaragoza, autores del plan del Ferrocarril Eléctrico Metropolitano de Barcelona y sus Ensanches de 1907. Este se aprobó mediante proyecto de ley por las Cortes a finales de ese mismo año en condiciones muy similares a las de Madrid. Se concedió sin garantía de interés ni subvención por parte del Estado, dictaminándose la reversión de las líneas en beneficio de este úl-

\footnotetext{
47 AVM, LAAM, sesiones del 13 de agosto de 1920 y 29 de abril de 1921.

48 AVM, LAAM, sesiones del 22 y 29 de abril de 1921.

49 Salmerón, 1992 y Armengol, 2012, pp. 257-265.
} 
timo. El consistorio barcelonés interpuso recurso, reivindicó la equiparación del nuevo transporte a los tranvías y reclamó sus derechos de titularidad sobre el subsuelo de la ciudad, exigiendo el abono de un canon por su ocupación.

Los debates municipales sobre el proyecto de Muller y Zaragoza coincidieron con los momentos iniciales de la reforma interior de la ciudad, planteada ya formalmente tres decenios atrás por Ángel Baixeras. Su proyecto, consistente en la apertura de tres grandes calles (Gran Vía A, B y C), buscaba la conexión del Ensanche y el puerto, así como el esponjamiento y la eliminación del tejido urbano más degradado del centro histórico ${ }^{50}$. Su gestación se produjo en 1907 mediante convenio entre el Ayuntamiento y el Banco Hispano Colonial, iniciándose las obras en los primeros meses de 1908. Como apunta Armengol, a finales de julio de 1911, tan sólo días después de la solicitud remitida por el Gobierno Civil al consistorio barcelonés para abrir una información pública sobre la concesión del ferrocarril metropolitano, aquel decidió introducir en los contratos establecidos con la entidad financiera para la urbanización de la Gran Vía A (después denominada Vía Laietana) la construcción de dos túneles destinados al tráfico ferroviario ${ }^{51}$.

El objetivo del Ayuntamiento de Barcelona era claro. Buscaba interferir en la tramitación del proyecto de Muller y Zaragoza reivindicando sus derechos sobre el subsuelo a utilizar por parte del futuro transporte y garantizando su intervención en el mismo, si finalmente terminaba materializándose la propuesta. Si bien es cierto que el consistorio tuvo propósitos de impulsar por su propia iniciativa el ferrocarril metropolitano, la sentencia del Tribunal Supremo sobre el Metro de Madrid terminaría descartando esa posibilidad. Sin embargo, la citada construcción de los túneles le otorgaría poco después una ventaja económica, coincidiendo justamente con la formación de la sociedad encabezada por el Banco de Vizcaya y el Banco Hispano Colonial para la definitiva construcción del Metropolitano en Barcelona.

A la altura de 1921, las autoridades municipales de Barcelona estaban de acuerdo en que el ferrocarril metropolitano debía ejecutarse «en el más breve plazo de tiempo posible». Sin embargo, también juzgaban que la sociedad concesionaria del nuevo transporte debía adoptar precauciones

50 Bohigas, 2001.

51 Armengol, 2012, p. 265. 
en sus trabajos para no lesionar los intereses del Ayuntamiento ${ }^{52}$. De este modo, el consistorio barcelonés fijó las condiciones que consideraba que aquella debía cumplir. Entre ellas sobresalía la presentación de un plan que modificara el original de 1907 mediante una operación de replanteo de las líneas, utilizándose los túneles de la reforma de la Vía Laietana para adaptarlo a las necesidades urbanas. Teniendo en cuenta la potestad del Ayuntamiento sobre los anteriores, su aprovechamiento por parte de una entidad concesionaria le permitiría un derecho de intervención en la construcción y explotación del nuevo transporte ${ }^{53}$.

A diferencia de lo ocurrido en Madrid, se abrieron desde un primer momento negociaciones entre la sociedad concesionaria del Metropolitano y el Ayuntamiento de Barcelona que derivaron en un convenio que tuvo cuatro conclusiones trascendentales. En primer lugar, el gobierno municipal vendería a la sociedad los mencionados túneles construidos de la reforma de la Vía Laietana por 850.000 pesetas. En segundo término, la sociedad Gran Metropolitano pagaría un canon anual de 45.000 pesetas en concepto de construcción y utilización del suelo y subsuelo hasta que las obras quedaran terminadas. En tercer lugar, el Ayuntamiento percibiría beneficios derivados de la explotación del transporte sobre la base de una escala ascendente en la siguiente forma. De las primeras 100.000 pesetas que excedieran de una recaudación kilométrica anual de un millón de pesetas por parte de la sociedad concesionaria, obtendría un porcentaje de un 6\%. En lo sucesivo, esa proporción inicial iría aumentando en un $1 \%$ por cada 100.000 pesetas que se sumaran a la recaudación kilométrica anual de la compañía, hasta alcanzar un máximo de un $15 \%$. Y finalmente, la compañía garantizaría al consistorio la percepción de 5.000 pesetas por kilómetro de explotación y año ${ }^{54}$.

El caso de Barcelona fue especialmente valorado por el marqués de Villabrágima tras hacerse con la alcaldía de Madrid a finales de 1921. Desde un principio, su objetivo fue aumentar los recursos municipales en un contexto en el que se debatían presupuestos extraordinarios para la realización o terminación de proyectos fundamentales para la ciudad, como el Matadero, la Necrópolis y obras requeridas para la mejora higiénica de los barrios populares. El cumplimiento de todo ello pasaba por el estable-

52 Arxiu Municipal de Barcelona (AMB), Llibre d'Actes del Consell Plenari (LACP), sesiones del 11, 18 y 25 de abril y del 4 de mayo de 1921 .

${ }^{53}$ La Vanguardia, 19 de abril de 1921.

54 El Imparcial, 7 de marzo de 1922. 
cimiento de nuevos arbitrios y la correcta aplicación de los ya existentes, como el que se refería a la ocupación de vías públicas y subsuelo, a aquellas empresas privadas que generalmente los habían esquivado, comenzando con el Metropolitano ${ }^{55}$. El primer paso dado por el regidor en este escenario fue concertar una entrevista con Otamendi, enfocada al tratamiento de los débitos de la compañía con el consistorio por el concepto de ocupación de la vía pública ${ }^{56}$. Paralelamente, se buscaría entablar un diálogo con el Ministerio de Fomento, mostrándosele el estado de opinión de los concejales con respecto al problema para lograr el reconocimiento de derechos mediante modificaciones legislativas ${ }^{57}$.

El marqués de Villabrágima expuso a la compañía liderada por Otamendi cuatro peticiones ${ }^{58}$. En primer lugar, el pago de un canon de construcción de 40.000 pesetas, extendido desde la fecha en que comenzaron las obras de la línea 1 hasta la terminación de las mismas. En segundo lugar, el abono de un canon fijo en concepto de ocupación de las vías públicas y del subsuelo de 5.000 pesetas por kilómetro de túnel de las líneas que quedaran en explotación. En tercer término, la instalación de focos luminosos de incandescencia en el exterior de los accesos a las estaciones de las líneas que estuvieran en explotación. Y finalmente, el reconocimiento para el Ayuntamiento de una participación directa en los beneficios de la empresa en las siguientes proporciones:

- 20.000 pesetas por kilómetro de explotación si la recaudación de la empresa no alcanzaba las 500.000 pesetas anuales.

$-4 \%$ de la recaudación si ascendía a 500.000 pesetas anuales.

$-3,5 \%$ de la recaudación si se encontraba entre las 500.000 y las 600.000 pesetas anuales.

$-3 \%$ de la recaudación si fluctuaba entre las 600.000 y las 700.000 pesetas anuales.

$-2,5 \%$ de la recaudación si se encontraba entre las 700.000 y las 800.000 pesetas anuales.

$-2 \%$ de la recaudación si superaba las 800.000 pesetas anuales.

55 AVM, LAAM, sesiones del 9, 15 y 20 de enero de 1922.

${ }_{56}$ La Correspondencia de España, 25 de enero de 1922 y La Voz, 4 de febrero de 1922.

57 AVM, LAAM, sesiones del 20 de enero y 10 de febrero de 1922.

58 La Voz, 6 de marzo de 1922, El Globo, 7 de marzo de 1922 y El Heraldo de Madrid, 8 de marzo de 1922 . 
Otamendi se dirigió por carta al alcalde de Madrid el 10 de febrero de 1922 para comunicarle que, aun encontrando ilegal el abono de cualquier canon municipal por el hecho de que contravenía los términos de la concesión del Ministerio de Fomento, se encontraba en su deseo «agradar al Ayuntamiento» accediendo a un convenio. En el Consejo de Administración celebrado por la empresa tres días después se discutieron las condiciones del mismo. La compañía se avenía a ofrecer un canon de construcción de 45.000 pesetas anuales y otro por kilómetro en explotación idéntico al que pagaba la Sociedad de Tranvías (ochocientas pesetas $)^{59}$. Sin embargo, esa propuesta fue entendida por la alcaldía como «mezquina en relación con la cuantía de la explotación y la utilización del suelo y subsuelo que requiere en exclusividad el Metropolitano» y quedó rechazada ${ }^{60}$. A modo de réplica, el alcalde presentó a los concejales una moción en la que se valoraba la posibilidad de utilizar un procedimiento de fuerza para acortar las distancias existentes entre las posturas de la empresa y del Ayuntamiento: la suspensión de las obras del Metro ${ }^{61}$.

En espera de lo que decidieran los concejales con respecto a dicha moción, las siguientes semanas se caracterizaron por un tenso cruce de declaraciones entre Otamendi y el marqués de Villabrágima. El primero denunció la campaña perpetrada contra su empresa, representada desde la alcaldía como «intransigente» $\mathrm{y}$ «enemiga del pueblo» ${ }^{62}$. A juicio del ingeniero, era una forma injusta de reconocer los beneficios que la compañía había generado para la movilidad intraurbana y el mercado laboral. Por esta razón, entendió como una necesidad convencer a la opinión pública de lo objetiva que resultaba la oposición de su empresa a los propósitos municipales, sobre la base de tres argumentos.

En primer lugar, Otamendi entendía que las obligaciones económicas de la compañía con el consistorio eran nulas. Ya se pagaban al Estado las contribuciones, impuestos y cánones exigidos a los ferrocarriles secundarios, no siendo legal que se le forzase a abonar tributos municipales no previstos en las cláusulas de la concesión del Ministerio de Fomento. En segundo término, el ingeniero explicaba las razones que llevaban a rechazar la entrega de un canon por kilómetro construido treinta veces superior

\footnotetext{
${ }^{59}$ La Época, 14 de febrero de 1922.

60 AVM, LAAM, sesión del 24 de febrero de 1922.

61 AVM, LAAM, sesión del 3 de marzo de 1922.

62 La Acción, 8 de marzo de 1922.
} 
al que abonaba la Sociedad de Tranvías, valorando que sus situaciones eran distintas. Así, mientras la segunda recibía directamente del municipio «calles perfectamente pavimentadas y alumbradas para que en ellas se instalasen sus postes y cables subterráneos y aéreos», los responsables del Metropolitano «invertían millones de pesetas en construir sus túneles» ${ }^{63}$. Y por último, Otamendi fijó las diferencias entre Madrid y Barcelona en lo que respectaba a las condiciones de construcción del nuevo transporte. En todo momento entendió que el concierto alcanzado en la capital catalana llevaba involucrada la venta que el Ayuntamiento hacía a la empresa «de unos soberbios túneles de doble vía en una de las calles más importantes» ${ }^{64}$.

El marqués de Villabrágima contradijo los argumentos de Otamendi y explicó el significado de la moción relativa a la suspensión de las obras. Aquella no representaba el corolario de una campaña arbitraria contra la empresa del Metropolitano. Por el contrario, era una lucha por recabar los tributos que lícitamente correspondían al municipio, acabando así con la perniciosa dinámica de años precedentes basada en la libre utilización de extensos espacios de las vías públicas ${ }^{65}$.

Lo cierto es que la actuación de la empresa del Metropolitano era consecuente con algunos puntos señalados por la alcaldía. Implícitamente, reconocía que la ocupación de vías públicas para la realización de las obras del transporte debía ir acompañada de la entrega de tributos al municipio. Así debió comprenderlo Otamendi, teniendo en cuenta que en un primer momento aceptó negociar con el marqués de Villabrágima y ofrecer cánones anuales relacionados con la totalidad de lo construido y los kilómetros en explotación. Si la empresa hubiese considerado que toda exacción de impuestos de estas características era ilegal, se hubiera opuesto de manera tajante a cualquier negociación. Para ciertos sectores de la opinión pública, el mero hecho de hacer ofertas suponía un acatamiento de la empresa al derecho ajeno y un reconocimiento de su deber, con lo cual, lo que se discutía ya no eran tanto los derechos de una y otra parte, sino la importancia de la cantidad económica que el Metropolitano había de pagar al consistorio ${ }^{66}$.

${ }^{63}$ La Época, 9 de marzo de 1922.

64 Ibid.

65 El Sol, 10 de marzo de 1922.

${ }^{66} \mathrm{La}$ Voz, El Sol, El Heraldo de Madrid, El Globo y El Imparcial (9 al 12 de marzo de 1922). 
El desentendimiento entre el marqués de Villabrágima y Otamendi llevó a que finalmente se votara, en sesión plenaria municipal del 10 de marzo, el decreto de suspensión de las obras. Se dio luz verde a la decisión de la alcaldía, no sin antes generarse un cisma entre los concejales. La minoría maurista consideraba ilógica la medida, entendiendo como nulas las atribuciones del alcalde para proceder de un modo como el que proponía en contra de los dictámenes del Estado. Asimismo, entendía que una interrupción brusca de las obras podía generar problemas de seguridad y orden público, teniendo en cuenta la cifra de trabajadores (unos 1.500) que quedaría en paro ${ }^{67}$. Por su parte, los socialistas comprendían que la moción impondría cortapisas en el elevado grado de autonomía del que hasta entonces había gozado la empresa gracias a las «amistades contraídas por sus representantes con poderosos cargos gubernamentales» ${ }^{68}$.

Las diferentes interpretaciones edilicias sobre la cuestión del Metropolitano se hicieron manifiestas en ese pleno municipal. Sin embargo, terminarían por cobrar su mayor gravedad en el momento en el que la alcaldía activó formalmente el decreto de suspensión de las obras diecisiete días después, una vez que Otamendi ratificó la negativa de la empresa a formular un convenio con el consistorio tras la reunión de su Junta de Accionistas celebrada el 17 de marzo ${ }^{69}$. Fue entonces cuando la cuestión del Metropolitano perdió su carácter local para asumir un carácter político-estatal.

\section{Entre la desautorización y el descrédito. El conflicto del «Metro» en las calles de Madrid y su resolución gubernamental}

El 20 de marzo de 1922 fue el día elegido por la alcaldía de Madrid para activar el acuerdo municipal relativo a la suspensión de las obras del Metropolitano. A primera hora de la mañana, el marqués de Villabrágima dirigió una última comunicación a Otamendi informándole de los procedimientos que se seguirían en esa operación, de la supuesta conformidad del ministro de la Gobernación, Pío Vicente Piniés, con su decisión y de las medidas de fuerza que el consistorio ejecutaría si la empresa utilizaba a sus obreros para boicotear su gestión ${ }^{70}$.

\footnotetext{
67 AVM, LAAM, sesión del 10 de marzo de 1922.

68 Ibid.

69 La Acción, 18 de marzo de 1922.

70 La Correspondencia de España, 20 de marzo de 1922.
} 
Poco después de ese último contacto, las estaciones del Metropolitano comenzaron a ser ocupadas por retenes de la Guardia Civil y de la Dirección General de Seguridad. La máxima autoridad de esta última institución, Millán Millán del Priego, justificó la custodia de la red como un medio de evitar los conflictos de orden público que pudieran producirse si se suspendían las obras y si la empresa del Metropolitano interrumpía, a su vez, la circulación de coches. A la vista de estas precauciones, el alcalde se puso en contacto con el ministro de Gobernación para pedir explicaciones sobre tales medidas. Aunque el marqués de Villabrágima daba por seguro el apoyo de Piniés en el conflicto, tras proporcionarle durante los días anteriores cuenta exacta de los acuerdos municipales tomados sobre este asunto, el ministro terminaría rectificando. Contradijo públicamente al alcalde, afirmando desconocer el fondo del problema, y definió la salvaguardia de las líneas como una medida inevitable para evitar un paro que provocase disturbios entre los trabajadores de la compañía ${ }^{71}$.

Para el marqués de Villabrágima la reacción de Piniés resultaba desproporcionada y contradictoria. A su juicio, no había que temer alteraciones del orden público, toda vez que el propósito del consistorio no era ni interrumpir el servicio de viajeros, ni dejar en situación de paro forzoso a los obreros de la empresa, a los que incluso se garantizaba la concesión de otras ocupaciones mientras se resolviera el conflicto. Visto todo esto, la conclusión a la que llegó el alcalde tras su entrevista con el ministro de Gobernación fue clara. El Gobierno se posicionaba a favor de los intereses de la compañía del Metropolitano y en contra de los municipales ${ }^{72}$.

A pesar de la negativa postura mostrada por el Gobierno con respecto al plan del alcalde, este decidió seguir adelante con el mismo. A primera hora de la tarde reunió en sus dependencias a los tenientes de los distritos. Se les transmitieron órdenes para acudir a los enclaves urbanos en los que la empresa tenía pozos abiertos para la extracción y vertido de tierras. Progresivamente, esas autoridades fueron llegando junto con técnicos municipales y guardias urbanos a puntos donde se situaban las casetas de obras instaladas por la compañía (Gran Vía, Puerta del Sol, Calle de Alcalá frente al Banco de España y Glorieta de Atocha). En todos esos escenarios se toparon con las fuerzas de seguridad dependientes del Estado, que se negaron a acatar las órdenes de la alcaldía. La cuestión del Metro-

71 La Voz, El Heraldo de Madrid y La Época, 20 de marzo de 1922.

72 La Correspondencia de España, 20 de marzo de 1922. 
politano derivaba así en un acontecimiento insólito: el enfrentamiento en las calles de Madrid entre representantes de las autoridades gubernativas y locales.

Las fuerzas de la Guardia Civil y de la Dirección General de Seguridad comenzaron a expulsar a los representantes del Ayuntamiento de Madrid de las zonas donde se desarrollaban las obras del Metropolitano. Se sirvieron para ello de procedimientos coercitivos, deteniendo a quienes se resistieron a obedecer sus órdenes. Esta fue la suerte que corrieron Nicolás Leopoldo Farge y Ángel Cubero, tenientes de alcalde de los distritos de Hospital y Buenavista; Eduardo Martínez Camarero, jefe de la Guardia Municipal de Madrid, y su segundo de abordo, Manuel Garrido. El alcalde también recorrió diversos lugares donde se realizaban obras junto con una sección de guardias municipales, tratando de penetrar sin éxito en los espacios dedicados a los tajos. La normalidad no se restableció hasta las doce de la noche, momento en el que el marqués de Villabrágima convocó una reunión de urgencia en el Ayuntamiento para adoptar cuatro acuerdos municipales de notable relevancia ${ }^{73}$.

En primer lugar, el Ayuntamiento de Madrid dispondría acudir al Gobierno en pleno para exponer su protesta contra los hechos acaecidos en las horas anteriores. En segundo término, rogaría a los diputados en Cortes elegidos por la provincia de Madrid la formulación de interpelaciones al presidente del Consejo de Ministros sobre los acontecimientos, llegando a cuanto consintieran los recursos parlamentarios para depurar responsabilidades y satisfacer las competencias municipales. En tercer lugar, acudiría nuevamente el 22 de marzo a los puntos donde quedaban instaladas vallas y tenderetes para los trabajos de construcción del Metropolitano, para derribarlos en caso de que el Gobierno persistiera en su irrespetuosa actitud hacia la Ley Municipal. Y por último, presentaría dimisiones irrevocables de los tenientes de alcalde en señal de protesta por las carencias que en términos de fuerza moral y material presentaba el consistorio a la hora de ejecutar los acuerdos alcanzados en sus sesiones plenarias $^{74}$.

Estas disposiciones fueron posteriormente comunicadas a los concejales en la sesión extraordinaria convocada por el alcalde el 21 de marzo.

73 La reconstrucción de los hechos a partir de: La Correspondencia de España, La Voz, El Heraldo de Madrid, El Sol, El Socialista, La Época y La Acción, 20 y 21 de marzo de 1922.

${ }^{74}$ La Época, 21 de marzo de 1922. 
Para entonces, las tensiones entre este y las autoridades gubernativas habían cobrado una gravedad difícilmente atenuable. Piniés ya había emitido una Real Orden por la que desautorizaba al consistorio, convirtiendo a su Guardia Municipal en un cuerpo armado dependiente del Estado ${ }^{75}$. También había dispuesto que las fuerzas de seguridad arrancasen de las calles el bando publicado horas antes por el marqués de Villabrágima, en el que declaraba su propósito de exponer al vecindario todos los hechos de la jornada del 20 de marzo para que aquel pudiera formar su opinión ${ }^{76}$. Los ediles trataron sobre todos estos puntos en el mencionado pleno, expresando un apoyo incondicional al alcalde. De esa postura únicamente se desmarcaron los mauristas, que consideraron que la alcaldía se había excedido en sus atribuciones actuando al margen de los cauces legales.

El conflicto del Metropolitano se convirtió en objeto de discusión de las sesiones del Congreso de los Diputados esa misma jornada del 21 de marzo. Las intervenciones más destacadas sobre esta cuestión fueron las realizadas por Saborit y por el propio alcalde de Madrid. El concejal y parlamentario socialista planteó al Gobierno la necesidad de tomar una actitud decidida en el conflicto del Metropolitano, proporcionándole soluciones eficaces que garantizaran el respeto del poder municipal. Asimismo, solicitó al Ministerio de Fomento y al propio Gobierno una mayor transparencia en las relaciones que podían mantener con la compañía dirigida por Otamendi, con el objetivo de averiguar la posible existencia de intereses económicos vinculados a los resultados de la empresa por parte de altos cargos estatales. Por su parte, el marqués de Villabrágima, buscó justificar la legitimidad con la que había actuado redactando el decreto de suspensión de las obras y adelantó su decisión irrevocable de presentar su dimisión de la alcaldía de Madrid, forzado a ello por la presidencia del Consejo de Ministros al negar cualquier tipo de jurisdicción al municipio en el tratamiento de una cuestión que únicamente competía al Ministerio de Fomento ${ }^{77}$.

Estas interpelaciones no evitaron la inmediata publicación de un Real Decreto del Ministerio de Gobernación por el que se nombraba alcalde de Madrid al conservador José María Garay Rowart. De esta manera, se despojaba a los concejales del consistorio de la facultad de elegir a sus regidores. Los primeros en reaccionar a esta decisión fueron los tenientes de

\footnotetext{
75 El Imparcial y El Heraldo de Madrid, 21 de marzo de 1922.

76 AVM, LAAM, sesión extraordinaria del 21 de marzo de 1922.

77 Diario de las Sesiones de Cortes (DSC), n. ${ }^{\circ}$ 9, 21 de marzo de 1922, pp. 238-260.
} 
alcalde, que dimitieron de manera irrevocable de sus cargos. A continuación, renegaron de sus atribuciones los delegados de los servicios municipales, con las excepciones de los vinculados a los ramos de Limpiezas, Puericultura y Carruajes. Y posteriormente, fueron las representaciones políticas del Concejo las que dieron a conocer su posición. La republicana acordó «protestar enérgicamente por los atropellos realizados y renunciar a todos los cargos que ejercían sus representantes», organizándose paralelamente desde sus juventudes federales mítines en defensa de unas mayores competencias municipales. La liberal mostró su negativa a admitir cualquier cargo por nombramiento del nuevo alcalde nombrado por Real Decreto. Y la maurista, a pesar de la contrariedad mostrada con respecto a las iniciativas del marqués de Villabrágima, persistió en el criterio inaugurado años atrás por figuras claves de su movimiento como Ángel Ossorio y Antonio Goicoechea. Para sus integrantes, el alcalde debía ser elegido por la corporación municipal, razón por la que acordaron protestar contra el nombramiento, acatándolo sólo «por respeto a los poderes constituidos» ${ }^{78}$.

Los socialistas no emitieron un comunicado oficial en esa jornada. Sin embargo, sus representantes en el municipio fueron los que más combatieron en lo sucesivo la recuperación de las alcaldías de Real Orden. Su enconada resistencia a la decisión tomada por el Gobierno se justificaba por tres razones. Primero, por una concepción que se fue consolidando desde su acceso a las concejalías en 1905, basada en el hecho de que la autoridad de los alcaldes como delegados gubernamentales imposibilitaba la estabilización al frente del municipio de una figura capaz de desarrollar una política acompasada con la transformación de Madrid ${ }^{79}$. Segundo, por la comprensión de que con el nombramiento gubernativo de los alcaldes se despojaba al Ayuntamiento de las franquicias de autonomía obtenidas con el paso de los años, cercenando la acción política municipal de sus concejales por el simple hecho de que los acuerdos que tomaran en lo sucesivo podrían ser revocados en cualquier momento por la superioridad ${ }^{80}$. Y tercero, por la consideración de que el consistorio no había realizado una acción punible que justificara el estado de excepción al que se le sometía, en

78 El Imparcial, El Heraldo de Madrid y La Correspondencia de España, 22 de marzo de 1922.

79 AVM, LAAM, sesiones del 1 de abril de 1910, 9 de mayo de 1916 y 10 de marzo de 1922.

${ }^{80}$ El Socialista, 15 de agosto de 1922. 
agravio comparativo con otras ciudades en las que no se suspendieron las atribuciones electivas de los concejales ${ }^{81}$.

El Gobierno confirmó la alcaldía de Real Orden de Garay Rowart el 1 de abril de 1922, justo el día en el que se producía la renovación de concejalías del Ayuntamiento de Madrid tras las elecciones locales celebradas el 5 de febrero anterior. En aquella jornada, las delegaciones de servicios y las tenencias de alcaldía de los diez distritos quedarían otorgadas por idéntico procedimiento, quitándose así al municipio cualquier ápice democrático evidenciado durante los cuatro años anteriores. El consistorio no recuperaría sus competencias para elegir a sus cargos hasta la Segunda República.

La actitud que el Ayuntamiento de Madrid había mostrado con respecto a la compañía del Metropolitano se entendió así en los términos de una rebeldía hacia las autoridades gubernamentales que estas no podían pasar por alto. A lo largo de los siguientes meses, y desde una postura más suavizada que la del marqués de Villabrágima, la alcaldía intentaría pactar un convenio con Otamendi que resultara satisfactorio para ambas partes. Sin embargo, los concejales elegidos por la ciudadanía en las urnas siempre clamaron por un reconocimiento de derechos que fuera más allá de las donaciones que ofrecía la empresa. Los conflictos de intereses relacionados con esta cuestión se mantendrían, con mayor o menor intensidad, hasta el estallido de la Guerra Civil.

\section{Conclusiones}

Entender el conflicto del Metro en Madrid exige valorar las interpretaciones contrapuestas que del mismo hicieron sus protagonistas. La oposición del Ayuntamiento no estuvo relacionada con los resultados que ese transporte traería para la ciudad. Su obstrucción fue deudora de una concesión cuyas condiciones se juzgaban inconciliables con los derechos que se debían reconocer al gobierno local. Ateniéndose a ciertas normativas orgánicas, el consistorio siempre vio como un deber prioritario la defensa de sus competencias en términos de gestión urbana, que consideraba vulneradas por el Estado y la compañía del Metropolitano. A su vez, esa postura se enlaza con el surgimiento de nuevas concepciones de gobierno municipal que corrieron en paralelo al proceso de transformación social

81 El Socialista, 27 y 30 de marzo de 1922. 
y económica experimentado por la ciudad en años precedentes. Con el transcurso de los decenios, se comprendió que las actuaciones del consistorio debían adecuarse al progreso de la urbe y a las necesidades de su población. Estas debían ser respondidas no por figuras que asumieran cargos ad honorem, sino por personalidades conocedoras de las coyunturas sociales y económicas en el marco urbano.

La perspectiva que tenía del pleito la compañía del Metropolitano era diametralmente opuesta a la anterior. Durante estos años se atuvo a las obligaciones fijadas en la Real Orden del Ministerio de Fomento que facultó la concesión de las obras en enero de 1917. Nunca se consideró sometida a la jurisdicción de dos autoridades distintas. Por el contrario, concibió a las estatales como las únicas conocedoras de las obras a realizar en el suelo y subsuelo de Madrid, por ser las que verdaderamente poseían elementos de juicio para determinar qué partes de las vías públicas debían ocuparse y cuáles no. Sin duda, se comprendían algunas de las alegaciones presentadas por el Ayuntamiento de Madrid en el conflicto, como evidencia la predisposición final de la empresa a otorgar un canon. Sin embargo, nunca se pensó en ir más allá de una donación. El sometimiento a otros requisitos exigidos por el consistorio no podía llegar per se, sino precedido de modificaciones legislativas de las que únicamente era responsable un Gobierno que finalmente optó por cercenar las franquicias de autonomía obtenidas por el consistorio madrileño en aras de interrumpir su actitud reivindicativa.

\section{Fuentes}

ARChivo de Villa de Madrid (AVM). ARCHIVo Histórico Nacional (AHN). ARXiU Municipal De Barcelona (AMB). Hemeroteca Digital (Biblioteca Nacional de España). HEMEROTECA DE La VANGUARDIA.

\section{Bibliografía}

ARMENGOL, Ferrán, «La configuración de la xarxa de transports urbans a Barcelona: societat, tecnología i política», GRAU, Ramón (coord.), Presència i lligams territorials de Barcelona. Vint segles de vida urbana, Arxiu Històric de la Ciutat de Barcelona, Barcelona, 2012, pp. 245-275. 
La batalla del Metropolitano. Protesta municipal y conflicto político en Madrid a finales...

ARMENGOL, Ferrán, «La regulación de los transportes urbanos en España: intervencionismo estatal contra autonomía local, 1859-1987», VI Congreso de Historia Ferroviaria, Vitoria Gasteiz, 2012.

BARKer, T.C. y RoBbins, Michael, A History of London Transport, Passenger Travel and the Development of the Metropolis. The Twentieth Century, Allen \& Unwin, London, 1974.

BradLey, Kevin F., The Development of the London Underground, 1840-1933: The Transformation of the London Metropolis and the Role of Laissez-faire in Urban Growth, PhD Thesis, Emory University, Atlanta, 2006.

Carballo, Borja, Pallol, Rubén y Vicente, Fernando, El Ensanche de Madrid. Historia de una capital, Ediciones Complutense, Madrid, 2008.

BoHIGAs, Oriol, La construcció de la gran Barcelona: l'obertura de la Via Laietana, 1908-1958, Ajuntament de Barcelona, Barcelona, 2001.

Cottereau, Alain, «Les batailles pour la création du Métro : un choix de mode de vie, un succès historique pour la démocratie locale», Revue d'Histoire $d u$ XIXe siècle, 29, 2004, pp. 89-151.

Cudahy, Brian J., Under the Sidewalks of New York: The Story of the World's Greatest Subway System, Stephen Greene Press, Lexington, 1988.

DARROCH, Nathan, «A brief introduction to London's underground railways and land use», The Journal of Transport and Land Use, 7 (1), 2014, pp. 105-116.

DAY, John R. y REED, John, The story of London's Underground, Capital Transport Publishing, Middlesex, 2001.

De Miguel, Santiago, La Gran Vía de Madrid. Historia social de una ciudad extinta (1860-1936), ACCI, Madrid, 2017.

De Miguel, Santiago, Madrid, un laboratorio de socialismo municipal: 19001936. Catarata, Madrid, 2019.

Delgado, Miguel Ángel, Destino Madrid: del tranvía al metro ligero, 150 años de historia, Consorcio Regional de Transportes de Madrid, Madrid, 2010.

DERRICK, Peter, Tunneling to the Future. The Story of the Great Subway Expansion that saved New York, New York University Press, New York, 2001.

Desabres, Pascal, «The Parisian Subway, 1880-1900. A Local or National Interest Line? On the Concept of Globalization», Business and Economic History On-Line, 1, 2003.

Evenson, Norma, Paris: A Century of Change, 1878-1978, Yale University Press, New Haven, 1979.

GonzÁlez YANCI, M. ${ }^{a}$ Pilar, El transporte, configurador del desarrollo metropolitano de Madrid. Del inicio del ferrocarril al metro ligero, siglo y medio de historia, Separata de Anales del Instituto de Estudios Madrileños, tomo XLVI, CSIC, Madrid, 2006.

GutiÉRrez, Diego, Aquellos tranvías de Madrid, La Librería, Madrid, 2001.

Halliday, Stephen, Underground to Everywhere: London's Underground Railway in the Life of the Capital, Sutton Publishing, London, 2001. 
Hallsted, Sheila (ed.), Métro-cité. Le chemin de fer métropolitain à la conquête de Paris, 1871-1945, RATP, Paris, 1997.

Hallsted, Sheila, Le Métropolitain: technologie, espace et creation d'identités urbaines dans le Paris de fin du siècle, Tesis Doctoral, EHESS, Paris, 1999.

HöHNE, Stefan, «The birth of the urban passenger: Infrastructural subjectivity and the opening of the New York City Subway», City: analysis of urban trends, culture, theory, policy, action, 19 (2-3), 2015, pp. 313-321.

Hood, Clifton, 722 miles: the building of the subways and how they transformed New York, John Hopkins University Press, Baltimore, 1995.

Hood, Clifton, «Changing perceptions of Public Space on the New York Rapid Transit System», Journal of Urban History, 22, 3, 1996, pp. 308-331.

KING, David, «Developing densely. Estimating the effect of subway growth on New York City land uses», The Journal of Transport and Land Use, 4, 2 , 2011, pp. 19-32.

Larroque, D., Margairaz, M. y Zembri, P., Paris et ses transports, XIXe-XXe siècles. Deux siècles de decisions pour la ville et sa region, Recherches, Paris, 2002.

LóPEz Bustos, Carlos, Tranvías de Madrid, EDIMAT, Madrid, 1998.

López Gómez, Antonio, Los transportes urbanos de Madrid, CSIC, Madrid, 1983.

MARTíneZ, Alberte, «Las empresas de tranvías en Madrid, del control extranjero


Manuel (eds.), Ferrocarril y Madrid: historia de un progreso, M. ${ }^{\circ}$ de Fomento, Madrid, 2002, pp. 149-179.

Magaldi, Nuria, Los orígenes de la municipalización de servicios en España. El tránsito del Estado liberal al Estado social a la luz de la municipalización de servicios públicos. INAP, Madrid, 2012.

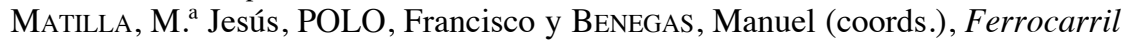
y Madrid: historia de un progreso, M. ${ }^{\circ}$ de Fomento, Madrid, 2002.

Matilla, M. a Jesús y Frax, Esperanza, «El metro de Madrid», Tst: Transportes, Servicios y Telecomunicaciones, 5, 2003, pp. 81-99.

MÉNDEZ, Ester, La Compañía Metropolitano Alfonso XIII: una historia económica (1917-1977), UNED, Madrid, 2000.

MoyA, Aurora, Metro de Madrid, 1919-2009: Noventa años de Historia, Metro de Madrid, Madrid, 2009.

Olivares, Susana, Antonio Palacios Ramilo (1874-1945): La arquitectura del Metropolitano y su idea de Metrópoli, Tesis Doctoral, UPM, 2015.

RASKIN, Joseph B., The routes not taken: a trip through New York City's unbuilt subway system, Fordham University Press, New York, 2014.

Rodríguez, Nuria, La capital de un sueño. Madrid en el primer tercio del siglo XX, CEPC, Madrid, 2015. 
La batalla del Metropolitano. Protesta municipal y conflicto político en Madrid a finales...

RuIZ PAlOMEQue, M. Eulalia, Ordenación y transformaciones urbanas del casco antiguo madrileño durante los siglos XIX y XX, Instituto de Estudios Madrileños, Madrid, 1976.

RUIZ ZAPATERo, José Luis, La innovación en los transportes urbanos en Madrid: la Compañía Metropolitano Alfonso XIII y la contabilidad en el período 1917-1935, Tesis Doctoral, UVA, 2015.

SAlmerón, Carles, El Metro de Barcelona (vol. 1), Terminus, Barcelona, 1992.

SÁNCHEZ PÉREZ, Francisco, La protesta de un pueblo. Acción colectiva y organización obrera. Madrid 1901-1923, Cinca, Madrid, 2005.

Vörms, C., Bâtisseurs de banlieue à Madrid. Le quartier de la Prosperidad (1860-1936), Créaphis, Paris, 2012.

WiLliams, Rosalind, Notes on the Underground. An Essay on Technology, Society and the Imagination, MIT Press, Cambridge, 2008.

ZAMORANO, Juan Carlos, El metro que pudo haber sido y no fue, La Librería, Madrid, 2012.

Zunino, Dahn, «The Circulation and Reception of Mobility Technologies: The Construction of Buenos Aires's Underground Railways», en FARI, Simone y MORAGLIO, Massimo (eds.), Peripheral Flows: A Historical Perspective on Mobilities between Cores and Fringe, Cambridge Scholar Publishing, London, 2016, pp. 127-151.

\section{Financiación}

Este artículo ha sido realizado en el marco de los siguientes proyectos de investigación: La sociedad urbana en España, 1860-1983. De los ensanches a las áreas metropolitanas, cambio social y modernización, PGC2018-096461-B-C41, Programa Estatal de Generación de Conocimiento y Fortalecimiento Científico y Tecnológico del Sistema de I+D+i financiado por Ministerio de Ciencia, Innovación y Universidades / Unión Europea. Fondo Europeo de Desarrollo Regional. MICINN/FEDER (Investigador principal: Luis Enrique Otero Carvajal) y «Ayudas para la realización de proyectos de I+D para jóvenes doctores», Ref.: PR65/1922409, Convocatoria 2019, entidades financiadoras: Comunidad de Madrid y Universidad Complutense de Madrid (Investigador principal: Santiago de Miguel Salanova). Asimismo, el autor ha contado con la financiación de la ayuda proporcionada por el Programa de Atracción de Talento de la Comunidad de Madrid, 2017, Modalidad 2 (Jóvenes doctores), Ficha: 2017-T2/HUM-5216. 


\section{Datos del autor}

Santiago de Miguel Salanova es doctor en Historia por la Universidad Complutense de Madrid y ejerce como becario posdoctoral del Programa de Atracción de Talento de la Comunidad Autónoma de Madrid. Entre sus líneas de investigación destacan la historia social y la historia de la movilización política en el Madrid del Sexenio Democrático y de la Restauración. Es autor de los libros Madrid, sinfonía de una metrópoli europea, 1860-1936 (Catarata, 2016) y Republicanos y socialistas. El nacimiento de la acción política municipal en Madrid, 1891-1909 (Catarata, 2017) y de diversos artículos publicados en revistas nacionales e internacionales. En adición, es el actual ganador del premio de la Asociación de Historia Social (noviembre, 2016) y del premio Earl J. Hamilton al mejor artículo español en lengua extranjera en Historia Económica otorgado por la AEHE. En la actualidad, ejerce como investigador del Proyecto Nacional I+D «La sociedad urbana en la España del primer tercio del siglo XX. Madrid y Bilbao, vanguardia de la modernidad, 1900-1936» (referencia HAR2015-65134-C2-1-P). 